\title{
Study on Coupling of Entrepreneurial Enterprise Growth and Enterprise Network Competence Based on a Random Network Model
}

\author{
https://doi.org/10.3991/ijoe.v12i12.6445 \\ Muyun Sun, Hong Gao \\ Hohai University, Nanjing, China
}

\begin{abstract}
In the 21st century, entrepreneurship has already become an important power in economic development, so entrepreneurial enterprises have turned into the research hotspot in academic circles. This paper establishes the benchmark model of entrepreneurial enterprises on the basis of random network model (GERT model). Modeling and simulation are conducted by a case study of actual data about entrepreneurial enterprise growth in Nanjing, showing the probability for entrepreneurial enterprises to grow into the mature period under the influence of the current enterprise network competence. Based on this, a comparison is made with the entrepreneurial enterprise growth model established. According to the modeling and simulation, the probability for entrepreneurial enterprises to grow into the mature period is increased under the influence of enterprise network competence. Therefore, suggestions of improving the enterprise network competence of entrepreneurial enterprises are proposed.
\end{abstract}

Index Terms-Entrepreneurial Enterprise; Enterprise Network Competence; GERT Model; Growth Cycle of Entrepreneurial Enterprises

\section{INTRODUCTION}

In the 21 st century, entrepreneurship has already been treated as the important internal power of activating various production factors and developing the economy. However, with the development of social economy, entrepreneurship is also faced with fierce market competition and high uncertain risk. Besides, low success rate of entrepreneurship and short life cycle of entrepreneurial enterprises are acknowledged facts. Meanwhile, entrepreneurship research has become the hotspot in theoretical circles, and enterprise growth is one of the core study issues. In order to reduce the possibility of entrepreneurship failure, social network is treated as the pipeline for entrepreneurial enterprises to contact and acquire external resources, so it has important significance for the growth of entrepreneurial enterprises. From the perspective of entrepreneurship, By grave and Hofer (1991) pointed out in their study process that the process of entrepreneurship was the process for the organization to continuously acquire resources, to identify opportunities, and to expand a new market and pit.

ZHUANG Jincai (2012) considered that a strong social relationship network played an important role in resource support [1]. WU Xuyun (2013) thought that network embedding had important significance for the growth of entrepreneurial enterprises [2]. A good inter-enterprise relationship will help enterprises acquire resources, share knowledge and enhance enterprise competitiveness (HE Jianhong, 2014). Therefore, enterprises must value their network and the relation with other organizations in the network. Moreover, they need to enhance their enterprise network competence and actively manage their network. According to the existing literatures, relevant researches about enterprise growth and enterprise network competence are still at the exploration stage, with many theoretical studies but few empirical researches. Practice research about enterprise growth and enterprise network competence should be further deepened.

\section{ENTREPRENEURIAL ENTERPRISES GROWTH AND ENTERPRISE NETWORK COMPETENCE}

Enterprise life cycle theory is a kind of simulation to compare enterprise development to living beings lifecycle. Enterprise life cycle widely accepted in academic circles and raised by Adizes (1988) can be divided into three phases and ten stages. The inoculation phase includes courtship stage, infancy stage and go-go stage; the growing phase includes adolescence stage, prime stage and stability stage; the aging phase includes aristocracy stage, recrimination stage, bureaucracy stage and death stage. As an early scholar to study enterprise life cycle in China, CHEN Jiagui (1995) put forward that China's enterprise life cycle could be divided into 6 stages on the basis of the studies of Adizes and the Japanese scholar Seiichi: courtship stage, survival stage, growing stage, mature stage, decline stage and transformation stage. All these theories widely believe that when enterprises are in courtship stage - growing stage, the business capital is weak, the resources are insufficient, and the system risk is high. After enterprises enter mature stage, they will gain relatively stable organization structures; their earnings can increase rapidly and the anti-risk capability is strong.

Domestic and overseas scholars' definitions about entrepreneurial enterprises are often given according to the starting time of enterprises, but the duration for enterprises to enter mature stage by passing courtship stage, survival stage and growing stage is restricted to many factors. There is no consensus of opinions in theory. Chrisman et al. (1998) defined that the courtship stage of enterprises would take 3-4 years by considering factors like industry, resources and enterprise scale. Brush (1998) considered that the duration for enterprises to enter and end survival stage should be 6 years. Boeker (1989) defined emerging enterprises as enterprises with a history less than 8 years. Li \&Atuahene-Gima (2001) verified this standard via empirical research. Chinese scholars HE Xiaogang and 
SHEN Yu (2008) treated enterprises not issuing IPO with a history less than 8 years as entrepreneurial enterprises. This paper defines entrepreneurial enterprises as enterprises in growing stage and before growing stage. In another word, the courtship stage of entrepreneurial enterprises is thought to last for 3 years; the survival stage will last for 3 years; the growing stage will last for 2 years. During this period, enterprise network competence plays a role in helping enterprises grow and enter mature stage smoothly.

With the arrival of network economic era, each enterprise has been put into the big network. Mutual influence and dependence exist between them and other organizations in the network. Mile (1986) made enterprise network competence concrete for the first time, laying a foundation for enterprise network competence study. Hakansson (1987) put forward the concept of enterprise network competence and treated enterprise network competence as the enterprise ability to improve the network status and to handle the relation with other organizations. MOLLER (1999) established network management capability, i.e. network visioning capability, relation combination management capability, network coordination management capability, and relationship management capability; this division method is widely recognized in China. Anna Grnadori (2005) considered that enterprise network competence was a mode to maintain constant connection by setting enterprise or enterprise branch as the node. The Chinese scholar REN Shenggang (2011) verified Moller's division for enterprise network competence through empirical study, and defined enterprise network competence as the dynamic capability of enterprises to acquire information and resources by identifying external network values and opportunities, and developing, maintaining and utilizing network relations at various levels.

According to social network theory and resource-based view, by combining with the above research achievements, this paper considers that enterprise network competence emphasizes the interactive relationship between organizations and has an important influence on enterprise performance. Enterprise network competence not only includes the ability to handle network relations but also contains the ability to improve the network status of enterprises. By applying division of enterprise network competence, enterprise network competence is divided into network visioning capability, network construction capability, relationship management capability, and portfolio management capability.

When enterprises develop into growing stage from courtship stage and survival stage, enterprise network competence will influence competitive situations of enterprises, improve the survival rate, and help enterprises acquire competitive advantages.

When an entrepreneurial enterprise is in the courtship stage, the enterprise scale is small and the biggest obstacle is capital weakness; leaders cannot clarify the future development direction of the enterprise. Network visioning capability can help the enterprise find a suitable partner in the network through network awareness. Network identification will evaluate the ability of the partner, and judge whether to form a cooperative relationship and establish a network alliance. Network positioning can determine the partner's status in the network. Only by clearly knowing their status and ability, can enterprises know their future development direction and realize the expected goal.
Entrepreneurial enterprises in survival stage need to determine their status in the network, to seek a suitable partner, and to overcome problems like high system risk and poor enterprise stability. Network construction capability can help enterprises positively mobilize various resources in the network, carry out cooperation with the outside, transform spontaneous production into exclusive input of cooperative partners, expand the enterprise scale, and reduce system risk. Through combination with other organizations in the network, an effective cooperative relationship can be established, and identification and utilization for external personnel will be strengthened. Moreover, a learning alliance can be founded, effective delivery of knowledge will be realized, and enterprise stability can be increased.

After entrepreneurial enterprises enter the mature stage, enterprises should realize smooth operation and enter the rapid growth period as soon as possible. Relationship management capability and portfolio management capability can help enterprises establish, optimize and coordinate the relationship with other organizations. When enterprises are in the growing stage, relationship management capability will help them establish and optimize a binary relation, realize optimization and continuous development of the relation with other organizations, and change simple cooperation and exchange into strategic alliance. Portfolio management capability will coordinate the pluralistic cooperation relationship in enterprise integration, integrate and reasonably distribute resources, efficiently utilize various resources distributed in the network, and generate a synergistic effect. For the cooperative relationship that has been established by the enterprise, judgment can be made for whether to maintain or terminate the cooperative relationship by assessing the value created by such cooperative relationship for the enterprise.

\section{BENCHMARK MODEL OF ENTREPRENEURIAL ENTERPRISE GROWTH}

The appraisal technique shown in the figure is GERT network model which is a new random network technique. In GERT network model, parameters are distributed randomly, and the influence relation will happen among various activity links at random. Do corresponding reactions have randomness at the starting or ending node of the activity or in the process? It can be used to analyze projects with complex situations and to control problems.

GERT network model often includes four steps when solving problems. Step 1: Problems are analyzed according to the practical situations, the flow chart of study is drawn, and GERT network model of the problem is established. Step 2: Various activities in GERT network model are defined, and values are assigned to parameters. Step 3: Solution is gained via equivalent function method according to signal flow graph theory; calculation can also be conducted by directly using parameters in the network, and the random problem is changed into decided problem solving. Step 4: simulation results of the model are gained and data are analyzed; problems are summarized and solutions are given.

GERT network model has already gained some achievements in the aspect of talent growth. Therefore, this paper attempts to study the issue of entrepreneurial enterprise growth via GERT network model. The growth of entrepreneurial enterprises can be treated as the transfer 


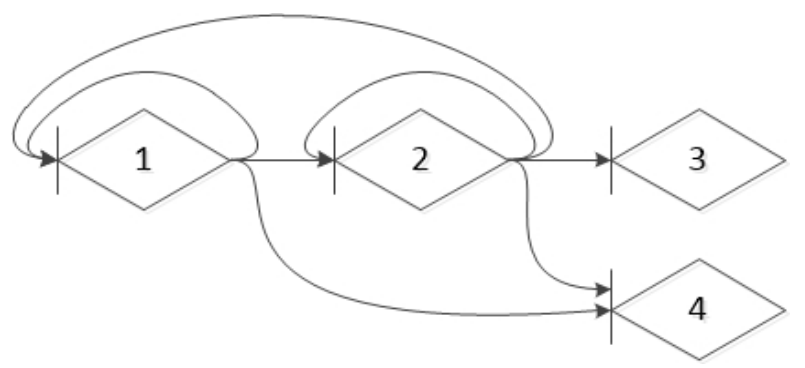

Figure 1. GERT network model of entrepreneurial enterprise growth

process between state and state of the system, and each step in enterprise growth represents different states in the system. When random network model is used for description, node means the system state, i.e. the growing state of enterprises. The arrow line connecting the nodes represents the transition probability relation between states. The input end of nodes can complete one activity only, and the output end of nodes can export one activity only, which is realized according to a certain probability. GERT network model of entrepreneurial enterprise growth is shown in Figure 1.

In GERT network model of entrepreneurial enterprise growth, state 1 represents that the enterprise is in the infancy stage; state 2 means that the enterprise is in the go-go stage; state 3 indicates that the enterprise is in the adolescence stage; state 4 signifies that the enterprise is in the death stage. State 3 is the target node of this paper. In another word, during the growing process, the enterprise often pays attention to whether it can grow into the adolescence stage. Activity $(1,2)$ means that the enterprise grows from the infancy stage into the go-go stage; activity $(2,3)$ represents that the enterprise grows from the go-go stage into the adolescence stage; activity $(2,4)$ indicates that the enterprise is terminated due to some difficulties before entering the go-go stage, and that the enterprise is in the death stage; activity $(3,4)$ signifies that the enterprise is terminated due to some difficulties before entering the adolescence stage, and that the enterprise is in the death stage.

Different states of entrepreneurial enterprise growth are different activities in enterprise development. This model can be used to discuss how an enterprise can enter the adolescence stage, how long it would take, and what the probability is. Meanwhile, it should be noticed that activity $(1,1)$ and activity $(2,2)$ reflect the difficulties encountered by the enterprise in the growing process as well as a series of processes to solve the problems. It means that the enterprise might form a circulation in a certain state $(1$ or
2), or form a circulation between state and state (1 and 2); finally, it will enter state 3 or state 4.

In GERT network model, moment generating function is used to calculate various probability distribution characteristics. The expression of calculating moment generating function at time $t$ is as follows:

$$
M_{i j}=E\left(e^{s t_{i j}}\right)=\left\{\begin{array}{l}
\int_{-\infty}^{+\infty} e^{s t_{j}} f\left(t_{i j}\right) d t_{i j} \\
\sum_{\text {all } t_{j}} e^{s t_{j}} p\left(t_{i j}\right)
\end{array}\right.
$$

In the formula, $\mathrm{Pij}$ is the realization probability from node $\mathrm{i}$ to node $\mathrm{j}$; $\mathrm{f}(\mathrm{tij})$ means the time probability density required by the realization, i.e. the probability distribution $p\left(t_{i j}\right)$.

Entrepreneurial enterprises are diversified, and require the support of various conditions during growth, so it is impossible to acquire a parameter suitable for all enterprises. Therefore, this paper analyzes the situations of entrepreneurial enterprise growth by a case study of entrepreneurial enterprises in Nanjing. According to data provided by various entrepreneurship carriers at national level such as China (Nanjing) Software Valley, Jiangning Development Zone, Nanjing Zijin (Jiangning)

Technology Incubation Special Park, and university science parks of different colleges and universities, the moment generating function of GERT network about entrepreneurial enterprises in Nanjing is gained via formula (1), as shown in Table 1.

According to previous analysis, there is only one direct path from node 1 to node 3: 1-2-3.

As per the moment generating function, if the transfer function $\mathrm{W}_{\mathrm{ij}}(\mathrm{s})$ from the initial node to the terminal node is gained, then the expression for realization probability of the terminal node in GERT network model is as follows:

$$
\mathrm{P}_{\mathrm{E}}=\left.\mathrm{W}_{\mathrm{E}}(\mathrm{s})\right|_{\mathrm{s}}=0=\mathrm{W}_{\mathrm{E}}(0)
$$

In the formula, $\mathrm{P}_{\mathrm{ij}}$ means the transfer probability, and $\mathrm{P}_{\mathrm{E}}$, i.e. realization probability can be solved on the basis of $\mathrm{W}_{\mathrm{E}}(\mathrm{s}) \mid$. When $\mathrm{S}=0$, the realization probability $\mathrm{P}_{\mathrm{E}}=$ $\left.\mathrm{W}_{\mathrm{E}}(\mathrm{s})\right|_{\mathrm{s}}=0, \mathrm{~W}_{\mathrm{E}}(0)=1$. It can be gained through calculation that Pbenchmark model $=(1-3)=3.27 \%$. This shows that the success rate for entrepreneurial enterprises to develop from courtship stage into growing stage is only $3.27 \%$, so their growth is relatively difficult. Most entrepreneurial enterprises will die before entering the growing stage due to various reasons.

TABLE I.

\begin{tabular}{|c|c|c|c|c|c|c|}
\hline Activity & $\begin{array}{l}\text { Transfer } \\
\text { function }\end{array}$ & Probability & $\begin{array}{c}\text { Distribution pat- } \\
\text { tern }\end{array}$ & Parameter/Year & $\begin{array}{c}\text { Moment generating } \\
\text { function }\end{array}$ & Transfer function \\
\hline$(1,2)$ & W1 & 0.1 & Normal Distribution & $\overline{\mathrm{t}}=3, \alpha=1$ & $\mathrm{e}^{3 \mathrm{~s}+0.5 \mathrm{~s}^{2}}$ & $0.1 \mathrm{e}^{3 \mathrm{~s}+0.5 \mathrm{~s}^{2}}$ \\
\hline$(1,4)$ & W2 & 0.7 & Constant & $t=3$ & $\mathrm{e}^{3 \mathrm{~s}}$ & $0.7 \mathrm{e}^{3 \mathrm{~s}}$ \\
\hline$(1,1)$ & W3 & 0.2 & Constant & $\mathrm{t}=1$ & $\mathrm{e}^{\mathrm{s}}$ & $0.2 \mathrm{e}^{\mathrm{s}}$ \\
\hline$(2,3)$ & W4 & 0.1 & Normal Distribution & $\overline{\mathrm{t}}=3, \alpha=1$ & $e^{3 s+0.5 s^{2}}$ & $0.1 \mathrm{e}^{3 \mathrm{~s}+0.5 \mathrm{~s}^{2}}$ \\
\hline$(2,4)$ & W5 & 0.6 & Constant & $t=3$ & $\mathrm{e}^{3 \mathrm{~s}}$ & $0.6 \mathrm{e}^{3 \mathrm{~s}}$ \\
\hline$(2,2)$ & W6 & 0.2 & Constant & $\mathrm{t}=1$ & $\mathrm{e}^{\mathrm{s}}$ & $0.2 \mathrm{e}^{\mathrm{s}}$ \\
\hline$(2,1)$ & W7 & 0.1 & Constant & $t=0.5$ & $\mathrm{e}^{0.5 \mathrm{~s}}$ & $0.1 \mathrm{e}^{0.5 \mathrm{~s}}$ \\
\hline
\end{tabular}

DEFINITION OF VARIOUS ACTIVITY PARAMETERS ABOUT ENTREPRENEURIAL ENTERPRISE GROWTH 
PAPER

STUdy ON COUPLING OF ENTREPRENEURIAL ENTERPRISE GROWTH AND ENTERPRISE NETWORK COMPETENCE BASED...

TABLE II.

EFFECT OF NETWORK COMPETENCE IMPROVEMENT IN DIFFERENT STAGES OF ENTREPRENEURIAL ENTERPRISES

\begin{tabular}{lccc}
\hline Scheme & Network competence & Realization probability $\mathbf{p} \mid \%$ & Comparison with benchmark solution \% \\
\hline Benchmark & - & 3.27 & - \\
$(1,2)$ & A & 4.15 & +0.88 \\
$(2,3)$ & B & 4.06 & +0.79 \\
\hline
\end{tabular}

IV. CONTRAst Model Of ENTREPRENEURIAL ENTERPRISE GROWTH

When entrepreneurial enterprises are studied, this paper uses the above model as benchmark model, so as to make a comparative study with entrepreneurial enterprises of improving network competence. In different stages of enterprise growth, network competence will play a role, which is represented with A and B in Fig2. GERT network model can be used to test the effects of network competence in different stages of entrepreneurial enterprise growth.

In order to make a contrastive analysis, hypothesis 1 is proposed: Entrepreneurial enterprises emphasize the improvement of network competence only in a certain stage (1-2 or 2-3, i.e. point A or point B). Through discussion with relevant experts, it is supposed that enterprise network competence can increase success rate of the enterprise in the current stage by $10 \%$, and meanwhile the variance is reduced by $50 \%$, which is within a reasonable range that can be accepted. Table 2 shows simulation results about the probability of transferring from point 1 to point 2 and then from point 2 to point 3.

According to the calculation, if the enterprise chooses to improve network competence in stage $\mathrm{A}$, then the probability of entering mature stage is increased by $0.88 \%$. If the enterprise chooses to improve network competence in stage $\mathrm{B}$, then the probability of entering mature stage is increased by $0.79 \%$. If the enterprise only chooses one stage to improve its network competence, then it can choose the stage of $(1,2)$, for the probability of entering mature stage is higher when enterprise network competence is improved at A.

Hypothesis 2: Entrepreneurial enterprises value the improvement of network competence in all stages; when the natural probability is low, the success rate is increased by $20 \%$ and the variance is reduced by $75 \%$, which is still within a relatively reasonable range.

According to the calculation, if enterprise network competence is improved at both stage $\mathrm{A}$ and stage $\mathrm{B}$, the probability of entering mature stage is increased. Therefore, it is quite important for enterprise development to increase the probability of entering mature stage to some extent by improving enterprise network competence.

\section{COUnTERmEasures And Suggestions}

In order to increase the probability of entering mature stage for entrepreneurial enterprises, this paper proposes suggestions from four dimensions of network competence, i.e. network visioning capability, network construction capability, relationship management capability, and portfolio management capability.

In order to improve network visioning capability, enterprises should fully consider key node relationships in the network by combining with their own characteristics. Organization system of the entrepreneurial enterprise is not perfectly developed, the capital is weak, connection

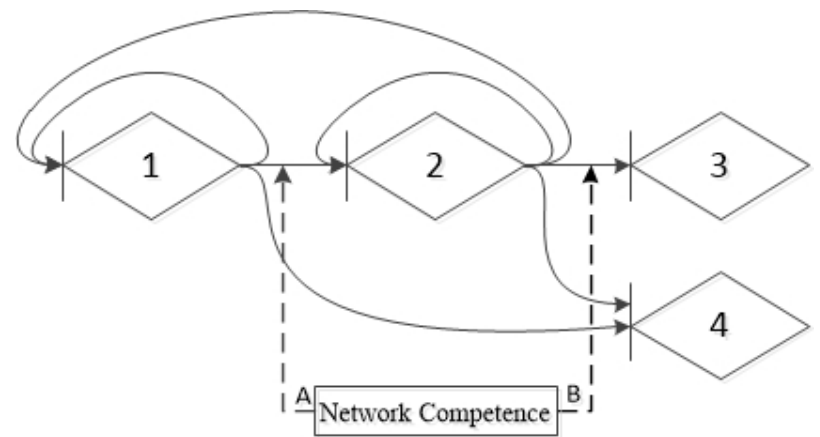

Figure 2. Network competence of entrepreneurial enterprises in growth

TABLE III.

EFFECT OF NETWORK COMPETENCE IMPROVEMENT IN ALL STAGES OF ENTREPRENEURIAL ENTERPRISES

\begin{tabular}{llll}
\hline Scheme & $\begin{array}{c}\text { Network com- } \\
\text { petence }\end{array}$ & Realization probi & $\begin{array}{c}\text { Comparison } \\
\text { with bench- } \\
\text { mark solution } \\
\text { \% }\end{array}$ \\
\hline Benchmark & - & 3.27 & - \\
$(1,2)$ & $\mathrm{A}$ & 4.93 & +1.66 \\
$(2,3)$ & $\mathrm{B}$ & 4.94 & +1.67 \\
\hline
\end{tabular}

between the enterprise and other nodes in the network is not close, and the intensity relation is weak. Therefore, enterprises should utilize entrepreneurial social capital and establish a relationship with other nodes; they need to reasonably allocate limited resources and to build the network by focusing on strategic emphasis. Meanwhile, an informal network relationship can be established. Such relationship is accepted by entrepreneurs, but is not bound by law.

Construction of enterprise network competence includes internal network construction and external network construction. Internal network construction requires scientific division of labor among various departments; their jobs and responsibilities should be clearly defined, and an integrated workflow and management mechanism must be established according to the overall situations. External network construction requires enterprises to expand the external network and value investment in relation resources. It will help enterprises acquire more scarce resources and establish competitive advantages. The existing relation resources should also be maintained, and enterprises must form a joint development relation with other nodes.

Relationship management capability means to manage and maintain the relationship with various nodes in the network at the organization level as well as to maintain the relationship with various nodes in the network at the individual level. Enterprises can enhance their relationship management capability by perfecting communication mechanism and trust mechanism. A good communication mechanism needs a good information transfer channel. In 
this way, when different opinions appear, an information exchange platform can be set up in multiple ways and the barrier of information transfer can be broken via modern channels. Meanwhile, information transfer channels also require the guarantee from systems. Both cooperative parties should formulate common rules and regulations, so as to maintain the operation of communication mechanism. Trust is the foundation of cooperation, so enterprises should improve the information sharing degree and eliminate worries caused by information asymmetry. Besides, an authoritative third-party organization should be introduced to fairly solve the conflicts.

Entrepreneurial enterprises need to establish a new competition concept when utilizing network resources. In another word, they should cooperate with other enterprises in the network, and realize a win-win result by starting from the angle of wholeness and integrality. Network utilization capability of enterprises is based on network construction capability and relationship management capability. The enterprise needs to realize macro control for the organization at the strategic level under the guidance of new concept. Enterprises should not only consolidate the existing network relationship and establish multi-aspect cooperative partners but also excavate potential network resources to lay a foundation for the future. Under the new competition concept, enterprise interest is not the sole premise. Instead, long-term development of the enterprise should be considered with a global view, so as to promote the cooperation with other enterprises in the network and to create a multi-win situation.

\section{REFERENCES}

[1] ZHUANG Jincai, SHA Kaiqing and CHENG Li, "Study on Evolution Law of Dual Network Embedding in Entrepreneurial Growth", China Industrial Economics, vol. 8, pp. 42-50, 2012.

[2] WU Xuyun, HE Xiaogang and HAO Yingli, "Research on the Relationship Between Entrepreneurial Orientation, Entrepreneur Social Network Emends and New Venture Growth", Science \& Technology Progress and Policy, vol. 5, pp. 78-84, 2013.

[3] REN Shenggang, MENG Yu and WANG Longwei, "The Measurement of Firm Network Competence and Empirical Research", Chinese Journal of Management, vol. 4, pp. 531-538, 2011.

[4] HE Jianhong, HE Changzheng and LUO Hua, "Network Competence, Strategic technology-orienteers and Formation of Innovative Enterprise", China Soft Science, vol. 2, pp. 127-137, 2015.

\section{AUTHORS}

Muyun Sun is a PhD student with the Business College, Hohai University, Nanjing, Jiangsu 210000 China, (shirley_yun@live.cn).

Hong Gao, was with Hohai University, Nanjing, Jiangsu 210000 China. She is now with the Department of Journal of Hohai University, (1098853594@qq.com).

Submitted 27 October 2016. Published as resubmitted by the authors 30 November 2016 